MA MAJOR RESEARCH PAPER

\title{
AWKWARD COMEDY AND PERFORMATIVE ANXIETY
}

\author{
ALANNA GOLDSTEIN
}

Supervisor: Jennifer Burwell

This Major Research Paper is submitted in partial fulfillment of the requirements for the degree of Master of Arts

Joint Graduate Program in Communication \& Culture

Ryerson University - York University-

Toronto, Ontario, Canada

May 4, 2011 


\section{Table of Contents}

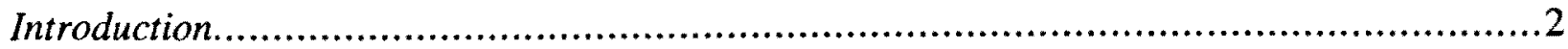

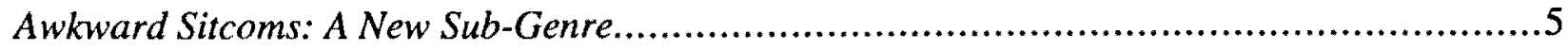

What is Awkwardness?

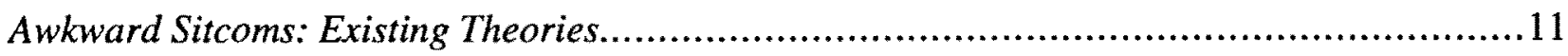

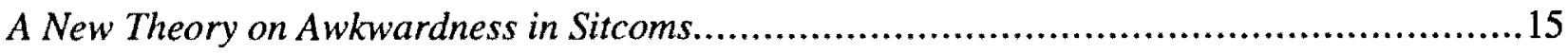

Why Study Comedy?

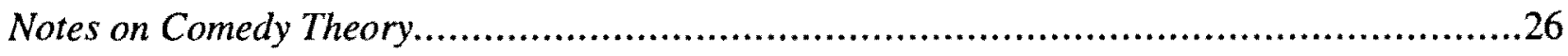

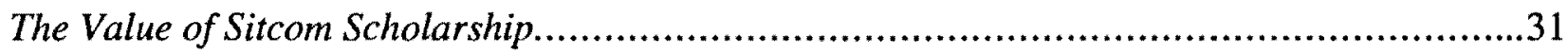

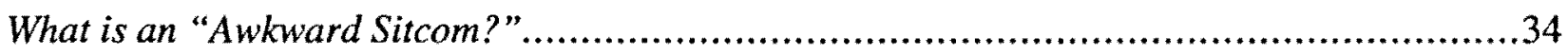

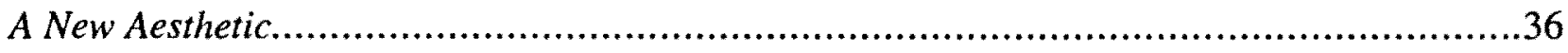

Self-Conscious Performance and Awkwardness........................................42

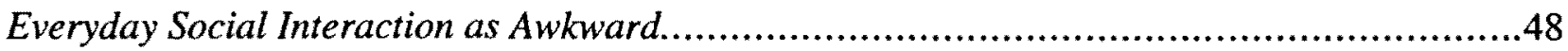

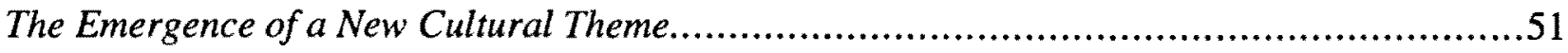

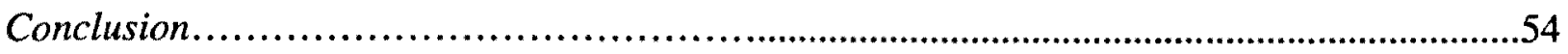

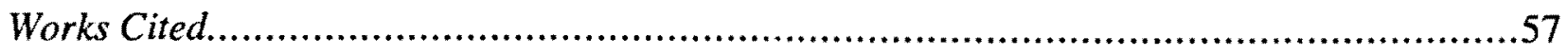




\section{Introduction}

As more and more of our daily social interactions are mediated and experienced through the screens of communication technologies, face-to-face moments of unmediated sociality has become the terrain for "awkward," unedited encounters, fraught with the potential for misunderstanding and communicative breakdown. Text messaging, instant messaging and social networking sites are increasingly replacing embodied forms of communication as the preferred method for building and maintaining even the most intimate of relationships. The ability to manage one's performance within these regulated and highly-edited communicative spaces consequently emphasizes the vulnerability of the embodied social self, engaging in real space and time. The potential for failure inherent to any embodied social interaction is increasingly prevalent as a theme across a variety of entertainment media, suggesting that concerns with embodied communication performances are widespread. In this paper I will illustrate how representations of this communicative breakdown and the resulting moments of "awkward" silence form the basis for a new sub-genre of television comedy that includes both the British and American versions of The Office, Peep Show, Curb Your Enthusiasm, Parks and Recreation and Modern Family, among others. I contend that the popularity of these programs is a function of their adoption of unique aesthetic elements that reflect and address anxieties surrounding changing communicative norms specific to life in a highly-mediated social environment.

Television comedy is an area of study that has generally been undertheorized by scholars. Worth noting, however, is the fact that television comedies are meant to appeal to the broadest possible audience and that to remain on air for more than a season, a sitcom must gather fairly substantial viewing populations. In his book Television Sitcom, Brett Mills argues that, far from representing "empty" entertainment, sitcoms actually reflect contemporary middle-class norms 
and values, and serve as a valuable tool for understanding what sets of behaviors and what kinds of people we seek to castigate through their humorous depiction. "The sitcom," explains Mills, "inevitably articulates the social concerns of the society for which it is made" (57). The question I am interested in, therefore, is not whether and to what degree sitcoms fail to challenge audiences, but rather why modern audiences find certain contemporary aesthetics and content funny, and what our changing sense of humor says about the extent to which modern communicative norms and anxieties-reflecting a particularly mediated mode of communicationnow occupy the popular imaginary.

After considering what makes an experience "awkward," I will make a theoretical link between the comedic depiction of awkwardness, and the increasingly mediated and self-reflexive nature of contemporary social life. Communication has become a set of "skills" to possess and perform correctly, and the wide availability of new media technologies increasingly allows for this performance to be "managed" and "constructed." The un-edited, unmediated, embodied space of face-to-face social interactions comes to be perceived as indeterminate, unpredictable and therefore prone to communicative error and failed performances. As more of our interactions occur through the mediated space of communication technologies, the embodied world is externalized as dangerous to the integrity of the self, and thus to be avoided.

In order to understand how contemporary comedies can reveal contemporary anxieties, it is essential to understand the reasons why we laugh. I will provide an in-depth explanation of Bergson's and Freud's theories of comedy to explain why a study of sitcoms is particularly useful for understanding the realities of our modern social world. Each of these theorists posits comedy as a strategy that works through, and thus renders harmless that which we would otherwise find grotesque, unsettling, or anxiety-producing. Henri Bergson saw comedy as a 
method for emphasizing the anti-social behaviour in which humans are prone to engage when they forget themselves as social beings-behaviour that is then corrected through the function of laughter. Sigmund Freud furthers this theory in his conception of anti-sociality as representing the tension between the desires of the individual and the restraints of civilization. By bringing these restraints to the surface through transgressive comedic depictions, comedy provides us with a sense of superiority over the object of humor, and therefore provides cathartic relief.

With this theoretical framework in mind, I trace the emergence of this new sub-genre of "awkward" sitcoms, outlining the ways in which their source of humor and their aesthetics have changed to reflect the primary social concerns of the era. In particular, I examine how the defining sitcom of the 1990s-Seinfeld-stands in contrast to, while paving the way for, "awkward comedy." I chart the stylistic changes that have occurred over the last decade regarding the television sitcom, such as a move away from using laugh-tracks to direct the audience's experience of the comedy, and the adoption of a documentary, "comedy-verité," style of filming, which highlights the "realness" (and rawness) of the characters and contexts being depicted. Specifically, I will examine the shift away from television comedies whose humor is derived from jokes that are situated within the "knowing" interaction between characters, as in Seinfeld, to a new form of comedy centered on humorous contexts, where it is the characters' lack of social skills and the resulting moments of awkward silence that provide the source of humor. The comedy-verité style ensures that we are privy to the characters' performance of their identities rather than to the psychology of their identities, representing a shift away from an emphasis on self-expression and towards an understanding of the self as an aestheticized construction.

Our heightened sensitivity to the performance of communication and our anxieties surrounding failures in performance as reflecting a failure of the self drives the popularity of 
sitcoms such as The Office and Modern Family. As rates of social anxiety disorder continue to rise in North America (Heimberg 29), gaining an understanding of how the performance of "correct" communication and appropriate sociality is implicitly reinforced through comedic depictions of "incorrect" communication performances is crucial for the construction of a more sympathetic model of communication-one that takes into account individual idiosyncrasy, insight and depth-rather than simply speed, cleverness and a surface performative facility.

\section{Awkward Sitcoms: A New Sub-Genre}

When BBC. Two aired the first episode of The Office on July $9^{\text {th }}, 2001$ in an obscure Monday night timeslot, little did people know that this offbeat show would go on to become a popular culture phenomenon, ushering in a new era of televised comedy. Replicated in an American version of the same name and spawning countless other shows of a similar nature, The Office's unexpected popularity represented a turning point in Western television comedy. By utilizing aesthetics that emphasized embarrassing situations and moments of miscommunication rather than simply providing well-delivered jokes and punch-lines, these sitcoms' preference for agonizing moments of silence over flawlessly-scripted exchanges of witty remarks has made communicative "awkwardness," rather than discursive "smoothness," into the new comedic norm.

What can account for this shift away from "the joke" as the primary comedic form of $21^{\text {st }}$ century sitcom? Why have sitcoms that not only depict awkwardness but that produce a feeling of awkwardness in audience members become so popular? As an experience that is generally avoided in everyday social interactions, it seems counter-intuitive that audiences are increasingly 
seeking out awkwardness as a form of entertainment. That this is so, as made evident by the rising popularity of new and recent sitcoms dealing directly with awkward situations, suggests that there is a growing awareness of the element of awkwardness inherent in everyday life. I argue that this awareness is not merely incidental, nor the trendiness of these sitcoms accidental, but rather that the heightened cultural sensitivity to awkward moments is a function of the novel ways in which we, as $21^{\text {st }}$ century subjects, now communicate with one another through technology.

The majority of the awkward situations depicted in these comedies occur in the course of face-to-face communication, suggesting that it is this sphere of sociality in particular that is perceived as being prone to miscommunication. As more of our social interactions come to take place in virtual spaces, it seems that there is less skill in, and tolerance for, the realm of embodied sociality, thereby resulting in an increase in actual and perceived moments of social awkwardness. In short, the more we immerse ourselves in technology, the less certain we are of ourselves as embodied social actors. And the more we engage with one another through the asynchronous, highly-edited channels of social networking sites, text messaging and email, the less comfortable we are in performing sociality under the pressure of immediacy inherent to face-to-face and voice-to-voice interactions. With this heightened sensitivity to the unpredictability of engaging through one's own voice and body exascerbated by the increasing ability for individuals to communicate from behind a screen, a newfound understanding of the realm of face-to-face communication as unbearably awkward ensues. 
What is Awkwardness?

Prior to presenting my argument that this cultural obsession with awkwardness has been brought about by recent technological and social changes, I undertake a general consideration of what exactly awkwardness is, and how depictions of awkwardness in modern sitcoms have been understood in previous scholarship. We all know awkwardness when we feel it, and yet most of us would be hard-pressed to pin-point what exactly this creeping, uncomfortable phenomenon means. While anxieties about the potential for awkwardness in social interaction are not new, the increased attention paid to communicative breakdown and social awkwardness in the sitcoms of the $21^{\text {st }}$ century points to a new set of fears and anxieties surrounding this phenomenon that must be addressed. Although there is little scholarship on the topic of awkwardness per se, there exists a significant amount of sociological and psychological work on the meaning and interpretation of sociality in general. In this section I consider the work of Erving Goffman and his theory of "face," in order to arrive at a more nuanced understanding of the specific experience of social awkwardness being depicted onscreen in modern sitcoms.

As one of the most prolific scholars to have written on the topic of everyday social interaction, Goffman understands social actors as engaging in what he calls "face-work." Goffman argues that, "Face is an image of self delineated in terms of approved social attributes" (Interaction 5). In any given social situation, individuals will generally engage in a performance of self that embodies the positive values of their particular society. Individuals expect this performance to be validated and upheld by all members engaging in an interaction, thereby allowing for sociality to proceed smoothly. "Much of the activity occurring during an encounter can be understood as an effort on everyone's part to get through the occasion and all the unanticipated and unintentional events that can cast participants in an undesirable light, without 
disrupting the relationships of the participants" (Goffman, Interaction, 41). Social interaction, then, far from being a natural effect of human beings coming together in space and time, is instead understood by Goffman as a precarious balancing act of differing personalities, motivations and skill levels. More often than not, participants fail to sustain this balancing act and one or more participants walks away having lost a certain amount of face. Goffman concludes that "In spoken interaction, spontaneous, "normal" involvement seems to be the exception and alienation of some kind the statistical rule" (Goffman, Interaction 134).

While Goffman does not specifically attribute the intense reliance on role-playing and face-work to the forms of sociality required under modern, capitalist social and work conditions, he does seem to view it as particularly important in shaping everyday interactions in the West. Without centralized traditions and mythologies to guide us, it is through our social interactions that everyday meanings are co-constructed. For Goffman, no innate personality is being expressed through language during conversation; instead the process of interaction requires individuals to slip into ritualistic roles. A conversation, says Goffman, "is a social system with its own boundary-maintaining tendencies; it is a little patch of commitment and loyalty with its own heroes and its own villains" (Interaction 113). These heroes and villains are produced in the act of conversing--those who possess the positive attributes of poise and tact are considered good social interactants, and they will often reap the benefits of such skill. Goffman observes that "poise plays an important role in communication, for it guarantees that those present will not fail to play their parts in interaction but will continue as long as they are in onc another's presence to receive and transmit disciplined communications" (Interaction 103). The ability to conduct oneself skillfully in everyday communication is considered a talent that one does not necessarily come by naturally. A degree of self-awareness is required, coupled with a tendency towards 
empathy and an element of quick wit. For those who do not possess this combination of talents, awkwardness in social interactions will inevitably result.

Modern sociality can be understood as the ability by all participants involved in a given interaction to abide by the invisible rules of sociality and maintain the guise of naturalness when engaging in a social performance. As Adam Kotsko explains in his analysis of the modern phenomenon of awkward entertainment, although awkwardness is often caused by individual actions, it can only be understood in a larger social context. "There exists a certain norm that, though often not explicitly stated, is regarded as both knowable and known by all members of a given community. Awkwardness is then related to this stable norm as its opposite or violation" (Kotsko 7). Awkwardness is the result of the disruption of sociality through the violation of social norms, combined with the awareness of the participants of this disruption. Awkwardness leaves those involved in the interaction without a mast to cling to, and it is up to the more socially-skilled individuals in the group to reinstate both the conversation's flow and the social norms whose construction was brought to light through their infraction.

For those responsible for the initial social infraction resulting in the awkward disruption of sociality, a normal degree of self-awareness may result in a physiological or psychological response that is often evident to other participants. Embarrassment, blushing and flustering, though seemingly innocuous responses to social infractions, can be dangerous for the integrity of the social encounter and for the face of those involved. "Flustering," says Goffman, "threatens the encounter itself by disrupting the smooth transmission and reception by which encounters are sustained" (Interaction 101). These resprnses, although originating in the "spoiled" face of one participant, can often spread to affect the entire encounter and all those involved. This social aspect of awkwardness, according to Kotsko, defines awkwardness as such. "Awkwardness," he 
writes, "is a breakdown in our normal experience of social interaction, while itself remaining irreducibly social" (15). Awkwardness cannot occur in isolation but rather spreads through contact, like a virus. Kotsko adds, "If you are observing awkwardness as awkwardness, then you are drawn into the awkward situation yourself" (8).

Awkwardness, then, can be understood as the psychological state of anxiety produced by the momentary revelation that sociality and all human symbolic systems are fallible constructions rather than firm realities. When communication breaks down, our sense of ourselves as truly coherent, fully-realized beings is shattered. "Behind many masks and many characters, each performer tends to wear a single look, a naked unsocialized look, a look of concentration, a look of one who is privately engaged in a difficult, treacherous task" (Goffman, Presentation 212). The routines of everyday life and the performance of the ritualized roles of social interaction that we adopt, serve to protect us from "the blank and numbing horror of the threat of chaos" (Silverstone, Ontological 595). However, as Anthony Giddens explains, while "the maintaining of habits and routines is a crucial bulwark against threatening anxieties" it is, by that very token, "a tensionful phenomenon in and of itself" (39).

Our need to keep the looming threat of chaos and existential uncertainty at bay puts us in a position of high alert with regards to our social interactions. Over the course of our socialization process, "what is mastered is an extremely sophisticated methodology of practical consciousness, which is a continuing protective device...against the anxicties which even the most casual encounter with others can provoke" (Giddens 99). This mastery requires a good deal of practice in social situations, an instinctual ability to read subtle social cwes and a degree of direction and instruction from one's elders. Expressing oneself through one's body-through the use of gestures, facial expressions, movement, tone of voice, attire--is not therefore an innate 
skill that one is simply born with, but rather the process of creating an adequately functioning social self through successful interaction is each individual's own particular challenge. As Goffman points out, an individual who fails to master the skills of sociality, "is likely to have such a baleful effect on the social life around him that he may just as well be called a faulty person" (Interaction 135). At stake in social interaction, then, is each interactant's sense of themselves as a worthy member of society. Repeated engagement in failed interactions suggests a fundamental lack at the core of one's being. The high-stakes nature of this game explains, perhaps, why individuals not confident in their abilities to navigate embodied sociality (through mastery of their body's various expressive functions), increasingly avoid it altogether-a point I will return to at a later stage in this paper.

It would seem, then, that awkward sitcoms are simply providing a space in which we, as viewers, can laugh at other people's social failures while remaining safely removed from their effects. If, however, as Kotsko has argued, awkwardness is social and spreads upon contact, then something more is happening when we watch awkward sitcoms. In these moments, we are not only consuming depictions of awkwardness, but we are deliberately putting ourselves in the position of experiencing awkwardness as a visceral, anxiety-producing sensation. What is the meaning of this contemporary desire to experience that which should bring us existential dread?

\section{Awkward Sitcoms: Existing Theories}

Awkwardness has emerged as a recurring theme in new sitcoms over the past decade, becoming entrenched as the underlying logic of nearly all comedic representations of social interaction. I will consider several existing theories for why this theme has emerged at this point 
in history, prior to advancing a new theory that posits the recurring theme of awkwardness in entertainment as addressing era-specific anxieties surrounding the realm of unmediated, embodied communication.

As the inaugural (and arguably still the best) of the awkward comedies, the UK version of The Office has inspired the majority of scholarship done on this sub-genre. Emma Tinker, in her work entitled, "Talking Cookie Jars and Tongue-Tied Bodies: Post-humanism and The Office" has posited that this series' focus on failed communicative performances represents a contemporary fear regarding the fragmentation of the self. Specifically, Tinker addresses the post-humanist anxieties that characters exhibit in trying to determine "the relative values of different bodies and selves" (761). This obsession with the meanings of bodies is a function of the increasingly blurred boundaries that exist between human and machine, us and them, normal and not.

The main character in this sitcom is David Brent. As a representative of the hegemonic subject of late-modern capitalism-white, heterosexual, able-bodied, middle-class, manager-he ought to feel secure in his position in this world, and in his relations with his employees. And yet, Tinker argues, it is often Brent, representing "a caricature of the humanist subject," who is positioned as "the other," unsure of the power he truly holds in a society that is increasingly moving towards a model of multiculturalism and inclusiveness (762). His anxiety is made palpable through his near continuous failings as a social communicator. "Obsessed with the desire to be admired, fashionable and attractive, he expresses his anxiety about his place in the world through a series of failed attempts at political correctness, an endiess repetition of faux pas that amounts to a nervous tic" (Tinker 762).

Brent's attempts to appear inclusive are belied by his inability to see past difference, 
often resulting in inappropriate comments that horrify others and yet seem to leave him unperturbed. Obesity, disability, colour and gender are all aspects of the body that Brent seems unconsciously to position as "other." Tinker observes, "To sustain his crumbling image of himself as the central, original figure from which all others differ, he must repeatedly denigrate the bodies of those around him" (763). Many of the most uncomfortable moments in The Office are therefore produced by Brent's inability to make himself speak and be understood, as his unconscious biases continuously clash against the respect and equality demanded by "others." For Tinker, "Far from controlling reality, Brent's language is often on the point of collapse. He lies, trails off, fails to finish sentences, misuses words and clichés, veers wildly between the linguistic codes of multiple forced poses. Desperate for wholeness, Brent is ultimately the most divided of all" (766). According to Tinker's reading of The Office, this faltering individual, trying to make sense of himself in a world that seems to have moved beyond him, is the subject of both mirth and derision, providing, through the tension created in the awkwardness onscreen, a space in which audiences can address their own anxieties regarding identities, bodies and selves.

While he does address the profound levels of awkwardness produced in sitcoms such as The Office, Adam Kotsko has argued that "awkwardness" in general is a wide-scale sociocultural phenomenon, specific to our modern, capitalist era. "We live... in an awkward age. We all know this on some level, all feel the awkwardness that threatens to engulf everything, all sense very acutely the terrifying possibility that civilization itself might collapse in a simultaneous worldwide cringe" (3). For Kotsko, the awkwardness depictéd in sitcoms such as The Office results from its focus on environments where strangers are forced to relate to one another through the false masks of workplace roles that are defined by the objectives of an 
impersonal organization. The result of this environment is alienation, and a certain degree of malaise towards one's work and one's work colleagues, resulting in often transparently weak attempts at getting along. Kotsko observes, "The Office portrays the modern workplace as bogged down in a condition of cultural awkwardness" (29). The character of David Brent is so superbly awkward because, as a man with little else of positive value in his life, he tries to identify himself fully with his middle-management position, embodying what he perceives to be the characteristics of a wise and benevolent boss.

According to Kotsko's critique of the modern-workplace, true personal identification with a work-place role, or with any institutionalized role for that matter, is impossible: "This attempted identification is what makes the character [of David Brent] so grotesque, because it is an attempt that necessarily fails" (43). David Brent's efforts therefore lead to more and more intense moments of awkwardness, as his actions are generally tinged with a degree of desperation and uncertainty that feed on each other to produce moments of almost unbearable tension. For Kotsko, the general feeling of awkwardness that haunts the majority of social encounters is inherent to the alienating conditions of late capitalism, in which detached roles-both personal and professional--come to replace attempts at authentic self-expression. People half-heartedly fill the roles that are expected of them, but no longer seem to know why they are doing so. Awkwardness is produced in these sitcoms, according to Kotsko, because of the discrepancy betweer: how characters feel, and what they are forced to present in the name of maintaining deeply entrenched socio-political hierarchies. 


\section{A New Theory on Awkwardness in Sitcoms}

Emma Tinker's discussion of awkwardness as arising from the uncertainty felt by the humanist subject in a world in which categories of inclusion and difference are increasingly blurred, and Adam Kotsko's understanding of awkwardness as arising from the alienating conditions of late capitalism, are both useful conceptual frameworks in my analysis of the semiotics of awkward comedies. However, what is missing from each of these analyses is a consideration of the role technology has played in changing how we view ourselves as social actors, the ways we communicate with one another and the meanings we attach to varying communicative activities. In the following section, I link these communicative norms and the increasing popularity of awkward comedies in addressing the heightened anxieties surrounding the performance of the self in everyday life.

It is not a coincidence that awkward sitcoms first arose as a genre in the early years of the $21^{\text {st }}$ century, and have caught on with mainstream audiences in the ten years since. The advent of communication devices over the past decade that allow for near-continuous connectivity have changed our individual sense of ourselves as communicating subjects, and have transformed the social sphere as a whole. The immersion of the self into virtual spaces has emptied embodied spaces of their relationship-building value. Friendship, love, sex, parenting, and indeed all forms of intimacy can now be engaged in from behind the a-synchronous and highly-edited space of a screen. This change in the nature of relating, combined with the larger cultural trend towards "reality-based" entertainment, has resulted in a form of sitcom that portends to show the "real" consequences of bodies coming together in space and time. And, more often than not, such "real" moments of face-to-face communication are represented as failing to maintain the smooth 
functioning of sociality, resulting in awkward silences, embarrassment for onscreen characters, and the squirming audience member at home.

Central to my argument that there exists a link between contemporary technological changes and newfound concerns regarding the self as a capable social actor is consideration of how the self is perceived in Western society and how this perception is shaped by changing conditions. Whereas modern conceptions of the self--drawing on Cartesian dualism--posited the existence of a real, authentic and whole being that the body expresses through action and language, postmodern conceptions of the self, such as those proposed by Anthony Giddens, expose this mind/body binary as fictional, positing instead the self as a "reflexive project" (35). According to Giddens, "the reflexive project of the self...consists in the sustaining of coherent, yet continuously revised, biographical narratives...In modern social life, the notion of lifestyle takes on a particular significance" (5). Under the conditions of late-modern capitalism, the dissolution of firmly-fixed social roles and the increased importance of consumption to economic and social life has resulted in a larger emphasis being placed on the role of the individual and individual identity. Individuals are compelled to (and required to) produce their own existential and social meanings through the construction of a "unique" self that is viewed--not as whole or complete--but as a project to be continuously worked upon. This obsession with determining one's identity results in a near-constant state of self-evaluation and simultaneous selfconstruction, as psychological states, bodily processes, and the expression of the "true" self in social realms through the adoption of semiotic markers-gesture, movement, voice, attire, physical fitness-are subject to ongoing critical scrutiny and subsequent adjustment. Explains Giddens: "the reflexivity of the self is continuous, as well as all-pervasive. At each moment, or at 
least at regular intervals, the individual is asked to conduct a self-interrogation in terms of what is happening" (Giddens 76).

While an individual's idea of themselves is important to the self-reflexive nature of contemporary social life, Giddens adds that "the reflexivity of the self extends to the body... where the body is part of an action system, rather than merely a passive object" (77). It is through the body that the individual makes their identity functional and thereby "real"- not only for themselves, but, crucially, for other people. The body, then, is "the fundamental means whereby a biography of self-identity is maintained; yet at the same time the self is also more or less constantly 'on display' to others in terms of embodiment" (Giddens 56). As a semiotic object and as a site for self-reflexive identity construction, the body's various expressions (gestures, movements, attire, fitness), as well as the activities the body engages in, must be rigorously monitored and controlled in order for the desired "self" to be both experienced internally, and expressed outwardly. This dual focus on the body puts considerable pressure on the individual engaging with others in real time, through face-to-face sociality. "Bodily selfmanagement...has to be so complete and constant that all individuals are vulnerable to moments of stress when competence breaks down-and the framework of ontological security is threatened" (Giddens, 56). The spectre of ontological stress that Giddens identifies as haunting the embodied self's performance in time is akin to Goffman's theory of "face-work" as a strategy for mitigating the potential for existential chaos inherent in any social interaction. Both these theorists recognize that skill at self-expression does not come naturally, but rather requires a lifetime of immersion in social worlds populated by other self-reflexive beings. The realm of embodied sociality is understood, then, as constituted by highly-constructed performances 
dominated by self-conscious interactants attempting to maintain their own sense of "authentic" identity while simultaneously managing others' interpretation of their bodily presence.

It is this pressure to perform a confident, coherent self on demand and in real time that is the central focus of the new sub-genre of awkward sitcom that is immensely popular among contemporary audiences. What makes these sitcoms unique is that characters' performances are almost universally characterized by failure, embarrassment, shame and awkward silences. Whereas Giddens and Goffman suggest that self-reflexive performance--though a difficult, often stressful endeavor-has become something akin to second nature for the individual interactant, awkward sitcoms suggest that the performance of a confident, socially adept, embodied self is a near-impossible task. Why has the embodied individual of our cultural imagination become too weak to stand on his/her own two feet? I am arguing that the increased immersion of selves and relationships into technological networks that are characterized by a-synchronicity and mediated distance rather than real-time, embodied performance, is resulting in newfound anxieties surrounding the use of the body as a communicative instrument, and is driving both the realitybased aesthetic behind the new sub-genre of awkward comedy, and the popularity these comedies have garnered.

What does it mean to display an authentic self when the body--as the central location for the reflexively-produced identity--is no longer physically present in social environments? How are notions of identity being reconfigured as individuals increasingly project themselves through the mediated screens of communication technologies? Early scholarship on the subject of the Internet and new media devices tended to adopt an enthusiastic tone regarding the liberating potential for identity play afforded $b y$ the anonymous nature of the technology. In her 1997 work, Computational Technologies and Images of the Self, Sherry Turkle provides a somewhat 
idealized account of the "adoption of multiple on-line personae," as contributing to "a general reconsideration of traditional, unitary notions of the self" (1104). Turkle argues that the Internet provides a space in which the bodily markers of gender, race and ability that determine power and privilege in the offline world can be subverted through online identity play. Sexual identity and desire can be explored, norms challenged, and a new, more inclusive way of relating would emerge.

While many of these positive aspects of identity play have been realized to varying degrees, the Internet in which such play could take place was the primarily text-based Internet of the 1990s. The first decade of the $21^{\text {st }}$ Century, however, has seen the Internet become a medium that relies on visual information as much as on text-based information. Additionally, the rise of reality television and celebrity culture, combined with the increasing popularity of social networking sites as a means of communication, has resulted in an online world populated by selves that no longer seek to remain anonymous. Rather, social networking sites represent "a third type of environment where people may tend to express what has been called their "hopedfor possible selves" (Zhao et.al. 1818). In virtual worlds such as Facebook and MySpace, along with online dating sites such as E-Harmony and Plenty of Fish, individuals want to make themselves known to others, but known in particularly constructed, tightly-regulated ways.

This production of a "hoped-for possible self" is accomplished through the asynchronous nature of networked interaction, which provides the time and distance necessary for the creation of highly-edited, virtual selves. In text messaging and instant messaging, individuals are able to craft their message with extreme precision, writing and re-writing perfected versions of themselves into being. On Facebook, the use of attractive photographs, clever quotations, and lists of interests/favorites, as well as the cultivation of online friends to enhance the appearance 
of popularity, create idealized online identities that can't be contested by others. Negative comments can be deleted, unattractive photos un-tagged (the process of removing one's name from the caption) and undesired acquaintances blocked. Networked communication, then, is all about managing representations. In their 2008 study, Zhao et. al., concluded that "Facebook users sought to make certain implicit identity claims aimed at generating desired impressions on their viewers, especially in terms of the depth and extent of their social ties" (1825). In such spaces, the construction of an aesthetically desirable online self--made possible through the user's complete control over their virtual experience--replaces the self-reflexive expression of the embodied individual who produces (and re-produces) their "true" identity through acts of face-to-face sociality. The maintenance of one's "face" on Facebook, or in any mediated space, does not elicit the existential uncertainty identified by Goffman and Giddens as inherent to embodied sociality, nor does it require the ability to relate to others through spontaneous and instantaneous moments of self-performance. Instead, each virtual "face" is its own, isolated entity, and each online interactant's sense of self-worth is bound up with their construction and presentation of a superficially perfect self that exists on its own, unchallenged, plane of reality.

The logic of the online profile is therefore similar to that of corporate branding policies, with emphasis placed on "impression management" rather than "authentic self-expression," as individuals strive for complete control over the message being sent. Under these conditions, the self comes to be viewed as a product to be worked upon, packaged and sold to prospective and current friends, acquaintances, employers and partners. The self as a social actor becomes embedded in technological networks that serve to "replicate subjectivity and merge the lived context with an apparatus of production, fostering the development of 'technobiographies' that write the self through the post-industrial logic of new media" (Freedman 202). Contemporary life 
is something that is now lived simultaneously in both online and embodied worlds, and any given experience can be reproduced and remediated in a myriad of intersecting ways. The line between authenticity and fantasy has been irrevocably blurred, leaving some social actors uncertain of how to be in person what they are in cyberspace.

Far from creating a space for un-tethered identity play, new media technologies and the internalization of the logic of profiles result in a view of the self as an aesthetic project that can be flattened into the space of the screen. Sherry Turkle, in her much less optimistic 2011 work regarding the impact of communication technologies on social relations, entitled "Alone Together," discusses the conscientious and at times obsessive production of the online self. "Like a sleek, gym-toned body, an appealing online self requires work to achieve" (251). The ability to produce an idealized version of one's identity in order to close down alternative readings of the self in virtual spaces stands in contrast to the myriad number of ways that the embodied self can be interpreted by others relating to it in real space and time. It is this discrepancy between what one wishes to be, and what one is perceived to be by a consuming audience that is at the heart of much of the awkwardness depicted onscreen today.

This flattening of the self into online spaces not only influences how we view our own identities but also changes how we relate to one another. In virtual spaces, relationships come to exemplify--according to Vincent Miller--Bronislaw Malinowski's concept of "phatic communication"-communication for its own sake, "more akin to an exchange of data than deep, substantive or meaningful communication based on mutual understanding" (390). In everyday social interaction, phatic communication (otherwise known ās "small talk") serves the function of maintaining the flow of sociality between strangers or acquaintances, so as to preserve the "face" of those involved. Phatic communication is therefore the opposite of 
intimacy - it is a strategy for engaging with the "other" without revealing too much of oneself. Intimacy, on the other hand, can only occur when chances are taken in social interaction, and vulnerabilities revealed. The unpredictability inherent to embodied social interaction, the backand-forth nature of conversation and the pace at which such interaction takes place, means that individuals engaging in voice-to-voice or face-to-face interaction are more likely to drop their social masks than those engaging through a-synchronous communications media. Although both Goffman and Giddens argue that the unpredictability of embodied social interaction can be experienced as existentially dangerous, it can alternately be experienced as trust-building and deeply fulfilling in a way that phatic communication cannot.

As social interaction moves into the disembodied, overwhelmingly a-synchronous spaces of communication technologies, it seems that spatio-temporal distance translates into psychological distance-a real life friend becomes a virtual "face," an "other" to be kept at arm's length through phatic rather than intimate communication. Social interaction in virtual spaces lacks the proximity necessary for vulnerability to be present and deeper relationships to form. Communication in these spaces is instead distilled to the level of idealized profiles "conversing" with other profiles through wall posts, private messages or simply the click of a "like" button beside a comment box. This move towards a "network sociality" (Wittel 2001), means that the maintenance of the social network through instances of phatic communication replaces Giddens' notion of the self as reflexively creating its identity through instances of embodied communication and dialogue with others. Indeed, the body comes to play an insignificant role in online communication, viewed as a hindrance to self-expression rather than as a place in which a full realization of the self can be actualized. In the absence of a body, the ontological stress of social interaction is muted, but the possibility of breaking through the cracks in a person's "face" 
to reveal the vulnerable self beneath is diminished as well. In virtual spaces, nothing need be revealed accidentally by failures of the body or tongue and a perfect "face" can be maintained indefinitely.

While control over the self and indeed over entire social interactions is afforded by the use of these new media technologies, is something lost in our experience of communication and relationships when the body is no longer involved? Hubert Dreyfus, in his 2001 essay On the Internet, thinks so. "When we are in the real world, not just as minds but as embodied, vulnerable, individual beings, we must constantly be ready for dangerous surprises. Perhaps, when this sense of vulnerability is absent, our whole experience is sensed as unreal" (Dreyfus 55). But perhaps it is our very vulnerability as fragile social beings that we are seeking to overcome by communicating almost entirely from behind a screen. The "unreal" of virtual spaces is sought out for its cushioning effect on sociality, allowing for the aesthetic appearance of relating without the existential danger of actually doing so. Under these circumstances, individuals retain their self-reflexive nature but do not necessarily gain the confidence and sense of validation made possible by the successful embodied performance of their desired identity. Instead, engaging in the construction of idealized online identities and relationships that cannot be made functional through embodied praxis, serves to create individuals who are uncertain of how to reflect themselves in their own everyday social performances. The result of this immersion of individuals in the "unreal" of virtual communication is that the experience of embodied sociality is multiplied in its existential meaning, with even mundane moments of social awkwardness constructed as something to be avoided entirely rather than simply worked through. And yet, though we seem to fear our own embodied vulnerability now more than ever, I do not believe that we have given up on the realm of embodiment altogether, as shown by the 
rising popularity of sitcoms that deal directly in representations of the embodied "real."The more we are able to avoid the spectre of awkwardness in our own lives, the more we seem to desire access to the existential danger (and potential emotional rewards) of imperfect beings coming together in our entertainment, reflecting a displacement of "the real" rather than a denial of its existence altogether.

While our feelings towards embodiment are undoubtedly complicated and often contradictory, as reflected by the new sub-genre of awkward sitcom, the overall trend in social interaction, particularly among younger individuals is towards further technological immersion. The widening perception of the embodied world as time-consuming, unpredictable, and requiring skill to negotiate effectively is resulting in a withdrawal of young individuals from the embodied social spheres that shape our ability to empathize, listen and adapt to the needs and feelings of others. Sherry Turkle's recent interviews with teenagers regarding their communication practices and use of new media technologies provide insight into the ways in which communication and relationships are understood by those who have grown up embedded within the network. Telephone calls and face-to-face interaction are perceived by interviewees as too direct, too unpredictable and potentially too revealing, because they sometimes result in awkward pauses, hesitancies and the breakdown of smooth communication flows. A willingness to make oneself vulnerable to others by engaging in long conversations that serve little instrumental purposeonce a hallmark of adolescence-is being replaced by a desire to "sell" one's friends on a wellcrafted, aesthetic version of oneself that can't be directly contested. The ability to perform an idealized version of the self is not possible in the realm of embodied scuiality, and so individuals raised with the network always close at hand increasingly prefer the distanced sociality of 
mediation to other forms of interaction. Today's teens, argues Turkle, "are among the first to grow up not necessarily thinking of simulation as second best" (17).

Face-to-face sociality is a spontaneous, yet highly practiced art-form that requires a degree of flexibility and willingness to fail that is not necessarily present in the mainly asynchronous, highly-edited realm of online interactions. As Giddens and Goffman have explained, spontaneous sociability requires interactants to feel comfortable in their own skin and to appear natural in their self-reflexive social performances. The less practice as spontaneous, embodied and potentially vulnerable social actors that we get, the more even everyday social interactions come to be seen as high-stakes games wherein our very sense of ontological security is on the line. Teenagers such as those interviewed by Turkle are increasingly retreating further into their screens, thereby producing a cycle of social aversion. Under these circumstances, it is not surprising that social anxiety disorders are seen to be increasing, as the social world itself, in all its uncertainty, is constructed as inherently anxiety producing.

Here then, in the space where technology, communication, relationships and ontological considerations collide, we are witnessing the elucidation of new sets of anxieties around the meaning of the everyday. And where there are new anxieties, a new kind of comedy will be born, exemplified by the trend in sitcoms towards a depiction of the varying physical environments of modern life-the workplace, homestead, school and public sphere-as messy spaces within which we have little control over who we will meet and how each interaction will proceed. The cubicles of the The Office, the living rooms of Modern Family--any space in which bodies come together to relate in real time--are represented as inherently awkward. Through their humorous depiction of social failure, these sitcoms provide audiences with access to the experience of embodied 
communication and the resulting awkwardness that they are increasingly able to avoid in their own highly-mediated, tightly-regulated social lives.

Why Study Comedy?

Why is a study of comedy valuable in understanding contemporary concerns and anxieties, and why sitcoms in particular? Why look to The Office or Modern Family as opposed to more serious fare for clues as to the anxieties plaguing contemporary society? In this section I examine the unique role the comic plays in addressing and mitigating anxieties at both a social and individual level, before moving on to an explanation of how sitcoms in particular fulfill these comedic functions. I will then undertake a semiotic analysis of several popular "awkward" sitcoms in order to demonstrate how their intense focus on, and production of, moments of awkwardness, can be understood as part of a larger conversation regarding the nature of modern sociality in general.

\section{Notes on Comedy Theory}

Many theorists have written on the subject of comedy, but there has been little agreement as to what makes something funny and what humour ultimately means. Nevertheless, in order to understand how the new sub-genre of awkward sitcom can be seen as reflecting anxieties around the self's ability to relate in "real" space and time, I will be utilizing theories of comedy that posit humour as serving a necessary social and psychological function. In particular, the work on humour done by Henri Bergson in "On Laughter" and Sigmund Freud in "Jokes and Their 
Relation to the Unconscious," provide a solid theoretical foundation upon which to build an argument for the necessity and value of a scholarship focused on forms of contemporary sitcom.

As social animals, humans are continuously implicated in a contradictory state of being, having to adopt particular social conventions that conflict with their individual desires. Comedy has often been theorized as operating in the space between the individual and the social in its ability both to highlight and mitigate deviant behaviour. While early classical thinkers such as Aristotle posited comedy as a moralizing agent, useful for instilling concepts of right and wrong (Hokenson, 26), modernist thinkers such as Fredrich Nietzsche and Henri Bergson--drawing on Darwinian evolutionary theory--see comedy as fulfilling a social rather than a moral function.

Bergson in particular emphasizes the social value of comedy. Writing during the alienating days of the industrial revolution, Bergson theorizes the comic as "something mechanical encrusted on the living," noting that it is "when the supple sociability of human life among one's fellows fails, that the comic erupts" (146). Jan Hokenson explains Bergson's "mechanical" not as an "offense against social conventions or any specific, relatively insignificant standards of propriety," but as "an offense against sociability itself, a more important human attainment than any local system of ethics or morality" (49). Human sociability--characterized by a system of culturally specific but widely adopted social conventions, norms and behaviours--is the only true universal, necessary for the survival of the individual within the group, and the species as a whole. Comedy tends to address this need for sociability through a focus on the failure of individuals to negotiate adequately the specific social norms and conventions of their culture. Comedy represents, therefore, " $x$ tension between full sociability and its defects or lapses" (Hokenson 57). 
Through our engagement with the comic, we express our understanding of our social world by laughing at representations of that which occupies a deviant position within it. This deviance is exemplified in the character of the comic butt (or sometimes comic hero)--the individual who lives outside the codes of sociability that keep our world intact. Under Bergson's theory, "we look down on the butt as deficient in comparison with ourselves, and, as comedy thereby ratifies our mocking, socio-moral superiority to the deviant, the norms of the social group are strengthened and renewed" (Hokenson 57). Brett Mills reiterates Bergson's point in his work on sitcoms: "Comedy often involves an understanding of who is 'us' and who is 'them,' with 'them' often forming the butt of jokes made by 'us"'(11). For Bergson, the creation of a binary between normal and abnormal through comedic depictions of transgressive actions reinforces the value of the social order and is the underlying value of comedy in general.

In Bergson's conception of comedy, then, maintaining a distance from and sense of superiority over those who fail to maintain the smooth functioning of sociability are key elements in producing the comic effect. "Laughter," says Bergson, "cannot be absolutely just. Nor should it be kind-hearted. Its function is to intimidate by humiliating" (188). The question of what exactly constitutes an action worth humiliating can only be understood from within the context of a particular social environment. If "awkwardness" has become a significant theme in contemporary comedy, what are the social values we are attempting to uphold by laughing at individuals and situations displaying this characteristic?

The Bergsonian theory of comedy as serving a social function--though incredibly versatile and useful--does not entirely address what we know to be happening when we laugh at something funny. Freudian comedy theory, rooted in the individual psyche's relationship to its social environment, provides the necessary link between the socially corrective function of 
laughter and the feelings of pleasure we gain from engaging with the comedic. Key to Freudian comedy theory is the notion of tension-release--or cathartic purgation--through laughter. This is accomplished through comedy's engagement with the taboo. Freud argues "that laughter is a result of comedy allowing usually suppressed thoughts to be expressed and is thus a vital 'venting of nervous energy' (Morreall 20). These suppressed thoughts are the antisocial aspects of our psyche that continuously bump up against the prohibitions imposed upon us by civilization.

By creating within comedy a space for the mimetic representation of antisociality, we ostensibly mitigate our desire to engage in it ourselves. Glasgow writes, "Affording a moment of release for the asocial urges deep down inside, for the "real self" that we normally reveal neither to ourselves nor to society at large, comedy...thus provides a link between the conscious and unconscious, the knowable and the unknowable" (253). Because "the universe of comedy exists on an ontological plane lower than that of real life" (Sutton 58), we are able both to identify with and distance ourselves from the actions taking place within that universe, thereby reinforcing through our laughter the triumph of our social self over our asocial urges.

Much like Bergson, Freud sees comedy as serving to maintain the supremacy of the social by representing situations, actions or characters that could otherwise challenge it. In Freudian theory, comedy achieves this effect, not through the creation of a marked distance from anti-social behaviour, as per Bergson, but by bringing us in close proximity to the darkest, most anti-social part of ourselves. According to Freud, humour "is dominatectby the emotion which is to be avoided" (228), for when we engagement with the comic, we "let into our conscious mind forbidden thoughts and feeling which society represses" (130). Comedy therefore requires a 
degree of identification with the taboos brought to the surface by the object of laughter, while also simultaneously providing enough space for the denial of any such identification.

By representing the "other" of sociability, we are able to confront its potential within ourselves and release it harmlessly. This is achieved through the use of what Dana Sutton has termed a "comic surrogate." This comic surrogate "is the ridiculous equivalent of any person, thing, situation, idea and so forth, in the spectator's own world, such as is capable of inspiring bad feelings in him" (Sutton 49). These "bad feelings," include pity, fear, anxiety and sexual aggression-namely the feelings that we tend to keep buried beneath the surface of our consciousness so we don't act on or even acknowledge them in everyday life. The comic surrogate's purpose is both to evoke the negative feelings associated with it and "to seem funny so as to evoke purgative laughter" (Sutton 51). This laughter "is a pleasantly purgative and entropy-achieving event both physiologically and psychologically" (Sutton 16). The cathartic event of laughter leaves the individual spectator feeling relieved, and the taboo feelings brought to the surface by the comic representation are safely returned to their place in the unconscious. The norms and codes of the "superior" social order are thereby re-established, and the individual resumes their place within the tenuous confines of civilization.

Just as Bergson's theory of humour provides a starting point from which to begin an analysis of sitcoms in order to determine what constitutes asocial behaviour (and thus proper sociality) in contemporary society, so too does Freud's theory of mimetic representation and comic catharsis provide a place from which to analyze what sorts of ideas, people and behaviours contemporary comedy produce the existential anxiety of awkwardness that must be purged. With this general framework of the psycho-social function of comedy in mind, it is now possible to move to a study of the situation comedy genre in particular in order to demonstrate how this 
seemingly banal genre possesses a unique capability for the elucidation and mitigation of the anxieties present within everyday social life.

\section{The Value of Sitcom Scholarship}

The sitcom genre has generally been dismissed as mere mindless entertainment, failing to live up to the transgressive potential of classic comedy due to its enactment within the hegemonic capitalist system of mass culture (Adorno 1957; Gitlin 1979). When sitcoms are discussed in any depth, it is usually within the context of a critical analysis of the ways in which such programming serves to reinforce dominant notions of sex, class, gender and race. (Jhally and Lewis 1992; Coleman 2000; Hatfield 2010). Rarely mentioned in analyses focusing on the (in)accuracy of representations within sitcoms, however, is the aspect of comedy theory and considerations of humour, that are, ostensibly, the driving forces behind the formation of such programming in the first place. A focus solely on representation fails to address adequately the position of sitcoms within our social world. When viewed through the prism of Bergson and Freud's respective theories of comedy, however, sitcoms can be understood as providing a timely social barometer, addressing contemporary concerns and anxieties through their comedic representations.

Understanding sitcom in this way situates it comfortably within broader theories on the role television as a medium plays in modern social life. As a cultural object, the meaning of television and of television programming is not fixed and immutable, but rather represents a space in which current and emerging norms and values, signs and sign systems can be addressed. 
As John Fiske and John Hartley explain, "television discourse presents us daily with a constantly up-dated version of social relations and cultural perceptions" (5). Truth in representation is not the aim, nor is it the value of television. As a medium, "television does not represent the manifest actuality of our society, but rather reflects, symbolically, the structure of values and relationships beneath the surface" (Fiske and Hartley 11).

Television, then, is a symbolic medium, delivering, as John Fiske says, "semiotic experiences, not programmes" (Fiske 59). The key to understanding the semiotic experience of television lies in appreciating its textual characteristics, rather than in attempting to locate its socio-political failings. As Fiske and Hartley explain, "what makes television an interesting object of study is that its programmes...constitute a gigantic empirical archive of human sensemaking" (xviii). Through an analysis of television programming, we can begin to understand the stories that contemporary society tells itself, and the conventions and codes used to tell them. We can come to understand what is valued, respected and normalized in our culture, and alternately, what is dismissed, buried or negated.

Though the language expressed in television programming might be-to a certain extentfixed within dominant cultural codes, the audience's relationship to the televisual texts is not. When we engage with television, we are not--as Adorno argues in his 1954 essay, "How to Look at Television"--simply consuming uncontested or uncontestable representations of everyday life that reflect and reinforce the status quo. Rather, the semiotic experience of television is characterized, according to Fiske, "by its openness and polysemy" (Fiske, Moments 58). As Roger Silverstone explains, "texts [are] to be seen not as complete or static but as incomplete and dynamic-requiring the activity of reading for their completion" (142). While the hegemonic power structures within which texts are created and delivered are difficult to challenge, the 
meaning of the texts themselves are never simply taken as given, but are always subject to (possibly resistant) interpretation by the reader/viewer engaging with them.

Chastising television programming for failing to subvert dominant social structures is therefore missing the semiotic "charge" of the medium. "The domain of entertainment deals in the interior pleasures of the meanings of texts, of self and of social relations; any resistance within it is semiotic, not social" (Fiske, Moments 72). Meanings presented via television programming are open to misinterpretation, appropriation and resistance. Television is a medium in flux, providing contestable experiences packaged as simple, uncontestable representations of particular interpretations of everyday life. As John Ellis explains, "The forms of television do tend towards the certainty of closure: the narrative forms which posit a resolution; explanatory forms that offer material that is graded and organized towards a particular conclusion. But television itself as a form tends towards the opposite, towards uncertainty and openness" (76). Indeed the structural openness of television means that within the span of a half-hour, a documentary on global warming could be interrupted a number of times with commercials for cars or air travel, political ads for green or conservative candidates and any other number of texts that contradict each other discursively. Television, then, as Raymond Williams' work on the medium's continuous "flow" has shown, provides a window into the messy space of human activity, thought and belief even as it arrives in homes and public spaces under the guise of mere entertainment.

The semiotically open nature of television, combined with its "everyday-ness," positions this seemingly innocuous medium at the centre of contemporary social life. Indeed it is the very mundaneness of television that gives it its cultural power, It appears to us as us. "The television medium presents us with a continuous stream of images almost all of which are deeply familiar 
in structure and form. It uses codes which are closely related to those by which we perceive reality itself. It appears to be the natural way of seeing the world" (Fiske and Hartley 4). The seeming naturalness of television means that it corresponds to "real" life, utilizing deeply embedded cultural codes and conventions to play out situations and address issues from a position once-removed. Though forms and narrative are exaggerated for entertainment value, the stories told and the characters telling them are like those encountered in everyday existence, thereby proving a mediated space for "the working out of significance" (Silverstone 164). According to John Ellis, "This...[is] television's distinctive contribution to the contemporary age: a relatively safe area in which uncertainty can be entertained and can be entertaining" (Ellis 76).

The mediated nature of television means that within the space of television programming, cultural anxieties around meanings can be addressed explicitly, and worked through safely. In this sense, "television is both shock and therapy; it both produces and discharges anxiety" (Mellencamp 246). This moment of shock is subtle, perhaps unrecognizable, in the sense that it is generated by a medium that purports to offer simple entertainment. Sitcom in particular, through its use of "mindless" humour mechanisms such as jokes and gags to immediately dispel any tension created, allows for our most deeply-rooted cultural fears and anxieties, our most taboo semiotic objects, to appear. In a world in which the "serious is not only prioritized, but normalized" (Mills 22), that which presents itself as funny is often trivialized as unimportant and dismissed as unworthy of academic inquiry. It is the seeming triviality of sitcoms however, and their deeply-entrenched positioning within everyday television viewership that point to their immense importance as cultural texts in need of scholarly inquiry. 
What is an Awkward Sitcom?

With this understanding of the social value of sitcom scholarship in mind, it is now possible to move to considerations of specific sitcoms in order to demonstrate how recurring representations of social awkwardness mark this theme as particularly relevant to contemporary audiences. Following on the heels of the original Office series, the majority of new sitcoms utilize aesthetics and content to produce a consistent effect of awkwardness which is dealt with and dispelled through the socially corrective and cathartic functions of laughter. This is accomplished through the ability of these sitcoms not only to represent awkwardness as a phenomenon but to include the audience member themselves in the experience of awkwardness. The increasing popularity of awkwardness as both a theme and an effect of sitcoms, indicates, I argue, a desire on the part of contemporary audiences to engage with the consequences of embodied sociality in order to work through anxieties surrounding it while simultaneously reinforcing the superiority of their own highly-mediated, decidedly non-awkward methods of relating via communication technology.

There are a number of new and recent sitcoms that fit within the sub-genre of "awkward comedy": The Office (UK and US versions), Parks and Recreation, Modern Family, Community, Peep Show, Arrested Development, Curb Your Enthusiasm, It's Always Sunny in Philadelphia, to name but a few. However, I will be focusing on The Office (both versions) as the original awkward sitcom, and on Modern Family as one of the most popular and mainstream awkward sitcoms yet to be produced. I will also use Seinfeld--the most popular sitcom in history--as the basis for a comparison of how these novel aesthetics result in a different kind of sitcom about different kinds of things, before providing specific examples from the awkward sitcoms under consideration to illustrate how contemporary anxieties are being addressed. 


\section{A New Aesthetic}

The aesthetics of this new sub-genre of sitcom are drawn from the reality-television and docusoap genre--forms that were just coming into their own around the end of the $20^{\text {th }}$ Century (Mills 30). This aesthetic--what Brett Mills has termed "comedy-verité"--allows for the representation of awkward situations that not only appear incredibly realistic, but that transcend the diegetic world of the sitcom and penetrate through the camera's lens to affect the embodied experience of the viewer at home.

The first and most obvious aspect of this new sub-genre of sitcom is the way in which the shows themselves are filmed. Both The Office and Modern Family use the premise that a documentary crew is following the characters around in order to "capture" their everyday existences. The hand-held shooting style, use of talking-head interviews, and propensity for characters to look at the cameras directly mimic typical reality-television formatting and highlight the "realness" of the characters and actions taking place, marking a definitive break from the earlier sitcom format that tended towards a more traditional, theatrical aesthetic. Explains Brett Mills, "conventionally, sitcoms are shot as if the performance was taking place in a proscenium theatre, with the audience positioned as the fourth wall" (32). In this new subgenre of comedy, however, the camera follows the characters through their lived experiences, thereby generating the feeling that these are not actors performing for us, but real people who happen to have been caught on camera doing or saying funny things. This move away from theatricality and towards "realness" profoundly influences the way in which these sitcoms are received and the types of emotions they generate. We no longer experience the sitcom as a distanced object of entertainment for our amusement, but rather through the presence of the 
camera's penetrating lens, we are drawn into the world of the characters, able to vicariously experience their embodied "reality" as if it were our own.

A second aesthetic that marks these sitcoms as different from their predecessors is the elimination of the laugh track--a strategy to which sitcom had faithfully adhered since the beginning of the genre, borrowed from the days when television adopted the aesthetics of vaudeville theatre. As Mills observes, "In the sitcom...the laugh track...underlines the artificial, theatrical nature of the genre, and the fact that sitcom requires an audience for its existence to be at all meaningful" $(50)$. The laugh track also indicates the ways in which the sitcom is to be understood, providing the socially sanctioning effect of the laughter of others, even when one is watching alone. The laugh track helps to fulfill the function of humour according to Bergson by indicating to the viewer which actions are to be understood as ridiculous with regard to a particular culture's conception of sociality. The laugh-track stands in for the collective social body, and we are encouraged, as social animals, to join in on the pleasure of corrective humiliation.

Without the laugh track however, the audience as representation of the social body loses its footing, leaving each individual audience member to determine for themselves what constitutes appropriate sociality. Whereas earlier sitcoms' representation of social awkwardness and miscommunication would have generated (laugh-track) laughter, now the awkward silence experienced between characters onscreen filters through the TV and into the audience's own world. Because this awkward silence is produced by a sitcom, however, its threat to the social order is mitigated, and the undesirable feeling of awkwardness that is dreaded--and increasingly avoided in favor of safe, tightly-regulated virtual spaces---is cathartically laughed away. 
This unique aesthetic creates a new sub-genre of sitcom which is often experienced as "not funny," at least not upon initial viewing. In fact the inaugural airing of the BBC version of The Office in July 2001 was not well-received, due partly to its obscure time-slot, and partly to the confusing position it occupied as a fake documentary about a paper supply office. It wasn't until it was aired again in a more popular time-slot that it began to appear on the radar of mass audiences and critics alike, eventually going on to a run in the U.S. and earning a 2004 Golden Globe win for best comedy series-the first British show in 25 years to receive such an honour. ${ }^{1}$

The initial dismissal of The Office as not representing "real" television comedy reflected the fact that it was attempting something radically new in terms of aesthetics and content that seemed to position it between genres. The decision in 2005 to adapt the British version of The Office to an American format was met with skepticism about whether the American market was ready for a comedy that broke so blatantly from previous sitcom norms (Beeden and Bruin 9). The long-running success of the U.S. version of The Office, however, and the fact that the comedy-verite style of sitcom has been adapted as the new norm, evident in the popularity of current top-rated sitcoms such as Modern Family, suggests that The Office's visual style and its propensity to produce awkwardness in the viewing audience is not a blip on an otherwise continuous sitcom trajectory. Rather, The Office represented a new type of television sitcom characterized most importantly by a new conception of humour that was not necessarily synonymous with funny--a conception that is evident in the ways in which the aesthetic influences the content of the sitcoms that adopt them.

In order to understand how this new sub-genre of sitcom addresses anxieties surrounding contemporary communicative norms, it is useful to compare them to the former reigning king of

\footnotetext{
${ }^{11}$ http://en.wikipedia.org/wiki/The Office (UK TV series)
} 
television comedy--Seinfeld. A hit during its nine-year run, Seinfeld uses the traditional theatrical-style of shooting and laugh-track narrative to provide the viewer with a fly-on-the-wall position in relation to the lives of the four main characters. The show is centered on the comedy of stand-up comedian Jerry Seinfeld (yet another nod to the Vaudeville tradition) and his three best friends as they go about their daily lives in 1990s New York City. Each character is narcissistic, neurotic and exceedingly juvenile in their own way, struggling to have it all--the good job, the solid relationship, the trustworthy friends--while actually wanting none of it. Seinfeld, then, provides a space for the working out of the post-modern confusion around what it means to have an adult identity when there are no responsibilities, traditions or expectations tying you down.

In its obsessive focus on the meaning of the seemingly insignificant, Seinfeld can be understood as representing a modern-day comedy of manners, whose "signature move was to subject everyday life activities to a minute and logical scrutiny that demanded to know why things are the way they are and not otherwise" (Mirzoeff 39). This relentless scrutiny generally took place within the space of the over-exaggerated dialogue between the four main characters. These dialogues "explored the boundaries that we use to create a sense of texture and meaning in everyday life" (Mirzoeff 43), and provided the audience with direct access to the thoughts, fears, and desires of the main characters as they struggled to negotiate a sense of identity and place in a world that is in constant flux.

Seinfeld's "verbal acuity," as Mirzoeff calls it (123), and the resultant laughter (both canned and real), which is a function of its observational cleverness and quick-witted dialogue in combination with its overly-theatrical shooting and acting style, stands in stark contrast to the new sub-genre of "awkward sitcoms," which are marked not by the presence of excessive 
verbiage, but by its very absence. In "awkward sitcoms," the lack of extra-diegetic laughter, combined with the documentary-style of shooting, create moments wherein the characters appear to us as "real" in their interactions. Rather than the ludicrous story-lines and exaggerated neuroses driving the humour in sitcoms such as Seinfeld, new sitcoms such as The Office and Modern Family focus on the boredom and mundaneness of everyday situations and character types as the source of their humour. Instead of the witty dialogue and endless punch-lines delivered with impeccable timing by well-trained actors, this new sub-genre of comedy presents reality-based social contexts populated by fallible human beings who cannot always make themselves understood in the ways they wish to be. The humour, then, is often to be found in the moments between dialogue, in the contexts in which actions take place rather than in the actions themselves. As Mills explains in his analysis of The Office, "narrative is downplayed and replaced by the slow accumulation of comic moments and idiosyncratic detail, both aspects often pinpointed by the documentary form but perhaps too subtle for the conventional sitcom look" (Mills 32).

The documentary-style of filming allows for close-up reaction shots that ostensibly provide us with access to the characters' "real" thoughts and emotions, which are often never actually spoken out loud. Humour, then, is produced not by what the characters offer us, but by what the camera reveals about the characters. This technique represents one of the key differences between this new' sub-genre of television sitcom and the previous era characterized by Seinfeld. Whereas in Seinfeld the characters engage in near-continuous banter as a way to address and resolve their anxieties regarding who they are supposed to be, in the new sitcom subgenre, due to the mediation of the camera lens, we are not privy to this same degree of selfexposure through fly-on-the-wall access to private conversations between friends and lovers. The 
focus, then, shifts from humourous self-reflection a la Seinfeld, to humour derived from (failed) attempts at self-performance. This shift in humour is not incidental, but reflects a fundamental change in the way we view our selves as social actors and our friends as social networks. Anxieties around who we are have given way to anxieties around how we present ourselves, reflecting an internalization of the notion that we are all objects for consumption, rewarded for our ability to created idealized, mediated, uncontestable versions of ourselves. Our friends are no longer intimate sounding boards so much as they are judgmental audiences.

This notion of the self as a highly-constructed performance that is prone to breakdown when confronted with the "real" of embodied interaction is what drives the popularity of this new sitcom sub-genre, while also producing the simultaneous effect of laughter and awkwardness that distinguish it. Indeed, there are two levels of performance at stake in these sitcoms--the characters' performance for the cameras filming them, and their performance in their "real," everyday interactions with other characters as captured by the all-seeing lens. Much of the analysis of this new sub-genre focuses on the former element of performance, but I will be drawing on the former in order to understand the relevance of the latter to our contemporary social selves. Although the infiltration of cameras into everyday spaces undoubtedly creates a heightened awareness of ourselves as objects for consumption, leading to awkward moments when we realize what we have exposed, our self-consciousness extends beyond a desire to perform for the camera to a desire to perform adequately with others in the spaces of the everyday. As more of our social interactions take place via edited, idealized profiles through asynchronous modes of communication, we are no longer certain of our ability to interact as poised, highly-practiced social beings in real-time, and the all-seeing eye of the comedy-verité 
aesthetic captures this reality through its depiction of everyday interactions as almost uniformly awkward.

\section{Self-Conscious Performance and Awkwardness}

The documentary premise of these sitcoms puts the characters of The Office and Modern Family in a position of self-consciousness with regards to the presence of the camera in their everyday lives. The knowledge that they are being filmed produces different effects, depending on the circumstances in which the characters find themselves. When the characters are witnessing someone else do something embarrassing or humorous within the diegesis of the show, the camera, as representative of the audience at home, is often appealed to directly--for mercy, conspiratorial laughter or sympathy. In both the UK and US versions of The Office for example, much of the humour is generated by the looks that the "normal" characters, (Tim and Jim respectively), regularly give the camera in response to the buffoonery taking place around them. Similarly, in Modern Family, characters often glance directly at the camera, appealing to the viewer at home for the sanity needed to deal with irrational or embarrassing family members. In these moments we are meant to identify with these characters as friends or colleagues, and are being asked to laugh with them at the circumstances in which they find themselves.

More nuanced however, is the way in which the camera asserts its presence as a "truthtelling" device during moments that would otherwise go missed, or remain private. Characters are often caught with their figurative pants down as the camera zooms in on momentary facial expressions that reveal painfully "real" emotions such as jealousy, sadness, fear and embarrassment. These fleeting moments are then doubled in significance by the characters' 
realization that they have been captured on film. Their eyes dart to the ever-watchful lens of the camera, whose presence represents the audience watching at home, and a degree of shame is added to their already painful private moment. The character is then required either to reassert their "face" in front of the camera, or walk out of the camera's frame of view altogether. The protagonists of such "realist" sitcoms "stumble uncertainly between public and private" (Tinker 757), perpetually unsure as to what they have revealed about themselves at any given moment.

This awareness that too much has been revealed to the camera, and hence to us, is particularly evident in the romantic entanglements of the early seasons of the U.S. version of The Office, in which secretary Pam is often caught secretly pining for her co-worker Jim, even as she maintains that they are just friends. In episode 3.10, we see Jim and his girlfriend Karen swapping Christmas gifts, laughing and hugging as they do so. The camera then quickly pans to Pam's desk, where her gaze is lingering on Jim and Karen, a pained, jealous expression on her face. She suddenly realizes that the camera has caught her out, and glances at the lens before quickly looking down, pretending to busy herself in something on her desk. In this moment, the "truth" of Pam's feelings for Jim are revealed, as well as something else. In the fleeting instant before her socialized shame kicks in, we see a flash across her face of anger, resentment, jealousy, sadness-in short, the anti-social tendencies that she, like all of us, works so hard to hide. This moment and these tendencies, which would otherwise have remained fleeting and private, are, within the space of these sitcoms, made available for consumption by the camera's lens.

As social animals, viewers often find it difficult to respond to these moments of "real" emotion with indifference. Through these filmed moment of private emotional turmoil, coupled with a public subjection of shame, the effect of awkwardness is produced, subjecting the 
audience to "the chaos that threatens on the other side of the ordinariness of everyday conventions" (Giddens 37). In order to deal with the tension of this moment, audience members are compelled to laugh, and yet can never do so in an entirely comfortable way. Once we have witnessed "the real" emotions of unguarded individuals, we cannot simply look away unperturbed. As Emma Tinker explains, "far from allowing viewers to luxuriate in the safe distance between "us" and "them," The Office forces us to share in its protagonists' embarrassment and discomfort. Comedy and empathy repeatedly disrupt each other as we laugh and squirm in equal measure" (Tinker 769). Without the presence of a laugh-track to reassure us that it is all only comedy, these moments of personal tragedy and ego-dissolution can be almost unbearable to watch. And yet, the audience not only understands them as humorous elements of a sitcom, but they also represent a new trend of capturing personal moments to produce awkwardness, that appears to be growing in popularity with the proliferation of more and more sitcoms that utilize these particular content and aesthetic forms.

Whether characters are looking deliberately at the camera, or shamefully catching the camera looking at them, their awareness of themselves as objects for consumption and interpretation by others provides comedic and cathartic appeal. The characters that are in control of their self-presentation appear confident, smirking at the camera with a knowing glance, and we must receive them in this way. When the cracks in the characters' performance of themselves are revealed by the all-seeing eye of the camera, however, their awareness of their vulnerability permeates the screen and we joyfully consume their failure even as we affectively feel their pain. Our desire to share in the awkwardness of these sitcoms, our willingness to make ourselves vulnerable to the "real" emotions of embodied individuals in non-mediated worlds, sits in direct contrast with our increasing desire to avoid the potential for awkwardness and vulnerability in 
our own lives. The more we move sociality behind the screens of devices, the hungrier we are, it seems, for access to the "authentic," uncontrollable emotions we have worked so hard to conceal.

The characters' awareness of the cameras in these sitcoms extends beyond mere collusive looks and captured moments of shame. At times, characters deliberately acknowledge the cameras and even sometimes perform for them, and ostensibly, for us. This element of performance is marred, however, by the fact that these characters are meant to represent real people, not actual performers; as a result, their attempts to be deliberately entertaining are often characterized by failure. This aspect of failed deliberate performance is nowhere more obvious than in the character of David Brent, from BBC's The Office. Significantly different about the character of David Brent, and to a lesser degree his US counterpart, Michael Scott, is the fact that he imagines himself to be a great entertainer with a future in show-business, a self-conception that guides his actions when in front of the documentary camera. Brent regularly addresses the camera directly, often forgetting that the cameras are there to film his work as a manager of a paper-supply company, rather than as a would-be entertainer. His attempts at performance are therefore often ill-timed and ill-met, producing many of the series' most painfully embarrassing moments.

David Brent is "a man of many moral shortcomings, whose main moral flaw is that he is too busy looking good, instead of being good (Nys 187). Brent's inability to ignore the camera is an acknowledgment made by the creators of this sitcom of the flaws inhe-ent in the realitytelevision/docusoap genre in general. The experience of awkwardness and the simultaneous effect of laughter in The Office are often generated in the space between what Brent imagines himself to be, and how he appears to his various audiences. A particularly cringe-worthy moment in episode 2.1 exemplifies how a failed attempt at being deliberately entertaining produces 
awkwardness both within the characters of the show and within the viewer at home. David, as manager of the Slough branch of the Wernham-Hogg paper-supplies company, is welcoming a new group of workers to his office--the result of a merger of two separate branches. The new workers are gathered in a meeting room, but before David can "welcome" them, he is preceded by their former manager and now David's new boss, Neil Godwin. Neil is everything David is not-handsome, confident, intelligent, witty and commanding of respect. Neil gives a brief yet funny introductory speech that is well-received by his former colleagues, and then introduces David, who tells Neil to "sit back and enjoy the show." In this instance, David--aware as he is of the camera's presence--decides to deliver a "performance" rather than a speech in an attempt to impress both his new employees and the audience at home with his entertainment skills. His effort amounts to the delivery of a very poor attempt at a stand-up comedy routine, filled with bad puns, offensive imitations of a disabled colleague, and the eventual devolution into a desperately unfunny Nazi-style march while shouting a non-sensical punch-line.

At no point in this speech does he address his new workers as individuals facing a stressful transitory period in their lives, who might benefit from some guidance from their new boss. Rather, for David, they are first and foremost an audience and he treats this speech as "an occasion to be the centre of attention. His intention isn't to put the staff at ease or make them feel welcome; his intention is to be funny-or, more accurately, to be thought funny" (McAleer 54). He also repeatedly looks towards the camera with a desperate gleam in his eye, willing the audience at home to laugh even as his employees do not. The speech ends with David sitting down in shame amid the horrified looks of embarrassment etched on the faces of the others in the room. Silence ensues until Neil steps in to move things along and the scene ends. 
Here, we witness the public dissolution of a man's ego as captured by the unflinching eye of the documentary camera. As viewers implicated in this scene by the camera's presence and by David's repeated glances directly at us, we cannot help but share in the horror experienced by David's audience, while at the same time recognizing with our more detached, cynical side the humour evident in this personal tragedy. Evans and Murphy explain the complexity of emotions experienced during such a (typical) David Brent scene: "Since we are not immune to humiliation, we look away from the television, laugh nervously, and wish we could bury his head for him. Oddly enough, we enjoy it too" (105). The rush of Freudian anxiety resulting from our identification with Brent's audience at this moment is dissipated through the effect of laughter when we realize that we are not the audience (and thank God for it). The social faux pas of vanity and an almost complete lack of self-awareness are epitomized in this instant by David as comic butt, and our laughter at him re-establishes our superiority with regards to him. "The humiliation we feel [for David Brent] reinforces our sense of goodness and character. Like humiliation proper, humiliation by proxy calls attention to our judgments of self and to our values" (Elia, 105). The "shock and therapy" experienced by our brush with the "social death" of another leaves us feeling stronger in our sense of ourselves as social actors. Though we might fail sometimes, we could never fail as badly as that.

In this scene, feelings of awkwardness are produced in the realization that David Brent is not only trying to make his audience laugh, but he is trying to make $u s$ laugh as well. While dealing with "unfunny" individuals who keep trying to make us laugh can produce intense feelings of awkward discomfort in real-life encounters, the mediated nature of David Brent's attempts at humour allow us to dispel the tension such an encounter produces through the effect of laughter at his expense. David's spontaneous, embodied performance of his desired self-image 
as a funny man is a resounding failure. The pressure of appearing in "real" space and time is too much for him, and the cracks in his persona quickly show through. That so much of this series is characterized by representations of failed embodied performances leading to awkward moments, reinforces the notion that the body as a site of social praxis is not to be trusted, and that perhaps it is better to avoid the possibility of failure altogether by simply performing the self from behind the safe space of the screen.

Everyday Social Interaction as Awkward

The camera's omnipresence in these sitcoms certainly makes itself known through the characters' self-consciousness in relation to it, whether they are colluding with it, hiding their emotions from it, or deliberately trying to capture its attention. The documentary premise of these sitcoms does, however, often allow the camera to simply blend into the background, becoming just another object in the room. In this way, the camera is able to capture an ongoing reality that is not always intended as a construction or an act of collusion for the sake of the audience at home. When left to its own devices, the camera presents us with a "realist" (albeit exaggerated) version of everydayness as it is to be understood in the $21^{\text {st }}$ century. In the diegesis of these comedy-verité sitcoms, such everydayness--filled with interactions between strangers, colleagues, friends, lovers and family members--is characterized in particular by near-continuous moments of communicative failure, misunderstandings, failed social performances and awkward silences. The objective eye of the camera, combined with the space for silences opened up by the elimination of the laugh track, creates environments where we, as the audience, are able to 
engage with mediated depictions of that which we fear in our everyday lived experiences--social awkwardness.

A minor scene in the hit sitcom Modern Family illustrates how the use of a comedyverité style of filming has been adopted by mainstream programming, demonstrating that awkwardness is increasingly constructed as inherent to all face-to-face relationships. In contrast to The Office's cruel, often unflinching portrayal of social failure, Modern Family is considerably gentler in its humor, showing the "reality" of everyday family life. The generosity afforded these characters is a reflection of an appreciably American sensibility, which shows that "while friends, family and colleagues may be a source of life's problems, they also constitute a significant support network" (Mills 42). While episodes of Modern Family tend to end on an uplifting note, they do still produce consistent moments of awkwardness within each episode through the documentary camera's all-seeing view on the interactions that take place between family members.

Phil Dunphy, as lovable, goofy "everydad," consistently plays the comic butt in this series through his nerdy demeanor and propensity to say the wrong thing at the wrong time (usually towards his wife Claire). In episode 1.19, Phil receives an iPad for his birthday, and is ecstatic. The camera finds him alone in his living room, sitting on the couch, stroking his new toy. "I love you," he says to the inanimate object in his arms, just as his wife walks into the room. She thinks he has murmured this endearment to her, and says, "I love you" back. Phil quickly hides his iPad against his chest and looks towards her, replying "Oh, okay." She continues on, walking out of the room, entirely oblivious to her secondary position in relation to his new toy. Phil, relieved to have not been caught by his wife, returns to stroking the iPad, but then suddenly realizes that there is a camera in the room. He looks towards it, embarrassed, 
stopping mid-stroke. Phil has been caught out in his indifference towards his wife when faced with the excitement of a new entertainment object, and his realization of what he has revealed causes a moment of awkward silence before the scene ends.

The humour in this scene is two-fold. Phil's response to Claire's "I love you" is both funny and awkward in the sense that his voice suggests confusion and indifference towards her pronouncement, which he hastily brushes off so that he can return to his new toy. This moment of mis-communication between spouses reflects a tension inherent within the institution of marriage between actively taking a vow to love someone forever, and the inevitability of coming to take that love for granted in the everydayness of it. The awkwardness of this scene is to be found in the taboo nature of revealing that vows of love are just words, and that spousal relationships are instrumental as much as they are emotional. Awkwardness is also generated in this scene through the camera's participation within it, as Phil realizes that the camera is there watching him, and his face changes to reflect the shame he feels at having been caught cherishing the inanimate while dismissing the human. This scene as a whole reproduces and addresses anxieties surrounding what it means to adequately perform love and intimacy, as well as acknowledging the ways in which technology comes to challenge and even replace embodied human relationships. Everyday interactions, even between spouses, are constructed within this sitcom as prone to mis-communication, suggesting that no relationship is free from the spectre of potential failure and the resulting existential chaos that is produced by the revelation of all sociality--even love--as performance. 


\section{The Emergence of a New Cultural Theme}

The past ten years have seen witness to a new aesthetic trend in television sitcom that can be interpreted, using Bergson and Freud's comedy theories, as addressing anxieties specific to our time. While all sitcoms have dealt to some extent with the comic foibles of socially awkward individuals, or the comic effects of miscommunication, the cushioning effect of the laugh-track and the distance created by the theatrical style of shooting has always allowed for the audience to mitigate any awkwardness through laughter. "It's possible," explains Brett Mills, "to relate the audience position in conventional sitcom with the Superiority Theory of humour, in which comedy functions to allow an audience to reassert their intellectual mastery over the misinformed, unaware and unintelligent characters" (Mills 63). In Seinfeld for instance, each of the characters are socially inept in their own way, and yet the obviously theatrical nature of the events and dialogue allows the viewer to maintain a safe distance in relation to the actions depicted onscreen. We are clearly watching other kinds of people when we watch Seinfeld, caricatures of types that do not exist in real life. The characters, as the ultimate embodiment of a 1990s ironic, postmodern, self-referential sensibility, seem to view themselves as caricatures, commenting on their own sordid lives and the lives of one another with little more than a smirk, and with no consideration for lasting consequences.

Seinfeld, then, can never be embarrassingly groan-worthy, because it is always a step ahead of the audience in laughing at itself. As Kostko explains, "Socially uncomfortable moments [in Seinfeld] are not dwelt upon, but become material for either detached bemusement or petty scheming" (23). We are never left in any doubt as to whether these characters are really as shallow, immature and pathetic as they seem. The obsessive need that these characters have to understand and articulate the meaning of seemingly trivial experiences reflects a particular set of 
anxieties and concerns specific to the 1990s urban experience-concerns regarding career choice and upward mobility, dating norms and expectations and the navigation of the confusing landscape of political correctness in an increasingly multicultural society. Issues of identity, choice and the articulation of an adult self are all at stake in Jerry, Elaine, George and Kramer's perversely inane everyday lives.

This obsession with negotiating (and often subverting) expected social norms, which provides the locus of the humour in Seinfeld, differentiates it starkly from the lack of coherent dialogue and explication of characters' actions that characterizes many of the awkward sitcoms that have since followed. Indeed, Mirzoeff, in his work on the subject of Seinfeld, sees the raucous dialogue, rejection of convention for convention's sake, and over-the-top characters of this landmark sitcom as epitomizing the social relations of its era, representing "a generalized optimism about the possibilities of the new global regime" (47). This optimism, he notes, was not to last, as the sobering events of $9 / 11$ ushered in the new century with the silencing effects of hyper-nationalism, right-wing conservativism and extreme paranoia. "The very verbal acuity of Seinfeld," he contends, "contrasts with the inarticulate and incoherent violence of the Bush era, epitomized by his smirk and Cheney's manifest evil" (Mirzoeff 123).

Although it is worth noting that it was right around this same historical moment that characters in sitcoms suddenly lost the ability to articulate themselves effectively, I do not believe that it is simply the uncertainty inherent in contemporary social conditions that has served to shut us up. Rather, the increasingly panoptic structure of $21^{\text {st }}$ century life, in which the proliferation of cameras throughout society renders all of us as potentially watchable all of the time, has combined with the increasingly mediated nature of interpersonal communication to create a heightened awareness of ourselves as consumable products. The sitcoms that epitomize 
our era, then, are ones in which we are witness to the hilarious nightmare of ubiquitous cameras filming failed performances, be they the deliberate performances of reality-television "actors" such as David Brent, who fail to convince their audience (both in the show and at home), or the everyday performances of context-based social actors such as Phil Dunphy, who fail to make themselves understood by those with whom they interact.

While the realm of network-based communication is bloodless and sterile, populated by perfect profiles editing perfected versions of themselves into being, the embodied world of fleshand-blood interaction is alternately populated by the carcasses of messy, imperfect social interactants who have failed to keep themselves and their message intact. The appropriation by a mainstream sitcom such as Modern Family of an aesthetic that forces audiences to confront failed sociality on a consistent basis indicates that concerns regarding social awkwardness are no longer the sole purview of anti-social nerds unable to rip their eyes away from fantastical computer-based worlds. The degree to which technology has come to permeate and construct the social interactions of nearly every member of society has made us all into anti-social nerds, no longer necessarily confident of ourselves when interacting with others without a technological barrier between us. The ability to exhibit "poise" and "tact," identified by Goffman as key to the smooth functioning of the social, sound like concepts from a bygone era. Instead, we are increasingly becoming isolated beings, bumping clumsily into others but lacking in the skills or sense to say we're sorry. That this fact has become the underlying theme of our everyday entertainment suggests that it is David Brent's awkwardness, rather than Jerry Seinfeld's cleverness, that is the new expectation for what it means to be an embodied social being in this world. 


\section{Conclusion}

It is always a hazard when reflecting on the impact of new communication technologies that one might come across as an alarmist or a Luddite, focusing only on the perceived dangers of change while failing to recognize that such changes in the ways we relate to one another do not automatically result in the end of sociality, civility and intimacy. I am not suggesting that the increase in reliance on mediated forms of communication is inherently destructive or negative; undoubtedly much good has come from such technologies and the ability for individuals to stay in contact while remote. However, I have witnessed within myself as well as within others a tendency towards choosing mediation over direct contact--text over voice, an evening spent alone with email over an evening spent among friends in the flesh--and have wondered at how quickly my own behaviour has changed in just a few short years of having technology handily by my side. In many instances, the knowledge that the network is there, and that sociality could occur if I wanted it, suffices for the "actual" experience. As Turkle explains, "digital connections...offer the illusion of companionship without the demands of friendship. Our networked life allows us to hide from each other, even as we are tethered to each other" (1).

What we lose in hiding from each other behind the mediated safety of the screen is a degree of tolerance, empathy and consideration for the messy imperfection of other people attempting to make themselves understood in person. A 2010 study of fourteen thousand college students conducted by researchers at the University of Michigan found that "college kids today are about forty percent lower in empathy than their counterparts of twenty or thirty years ago" with the majority of that decline having taken place since the year 2000 (Konrath et. al). Students in this study were less likely to agree with statements like "I often have tender, concerned feelings for people less fortunate than me" and "I sometimes try to understand my friends better 
by imagining how things look from their perspective." (Konrath et.al.). These findings are notably linked with the rise of social networking sites, with one of the study's authors suggesting that 'The ease of having 'friends' online might make people more likely to just tune out when they don't feel like responding to others' problems, a behavior that could carry over offline" (Science Daily, May 29, 2010). The insulation afforded by communication via machines has the effect of alienating individuals from one another when confronted face-to-face. The perfectly witty, attractive online friend we know may prove shy and reticent in the flesh--a fallible stranger whom we cannot understand, and who does not know how to understand us.

The ability to roll with the punches, make strangers feel included, and to laugh with rather than at other people are all subtle elements of sociability that are not necessarily a part of online life. The more immersed we become in aestheticized worlds the more "awkward" everyday social encounters appear to us. That "awkward" has itself become a trendy buzz-word thrown around by teenagers at the drop of a hat suggests that its looming potential to insert an unwanted dose of chaos into the smooth-functioning of sociability is increasingly perceived as a threat. The threat of awkwardness, depicted in a growing number of television sitcoms as the underlying logic of all embodied acts of communication, is linked not only to our anxieties surrounding others as unknowable entities, but to ourselves as adequate performers, capable of dancing the dance of sociability without the mediating mask of technology to protect us. Since, prior to the advent of ubiquitous communication technologies, bodies necessarily had to come together to live out the everyday, the fact that these spaces are increasingly depicted as ontologically dangerous because they are not subject to the tight controls of mediation suggests a changing notion of what it means to be an everyday social being. If we are willing to take our comedy seriously, as I suggest we should, then we can begin to see that while awkwardness has 
always been a facet of engaging socially with others, the degree to which it now occupies the popular imagination suggests that it is not just $a$ fear, but perhaps one of the central concerns of $21^{\text {st }}$ century life. 


\section{Works Cited}

"A Benihana Christmas." The Office: The Complete Third Season. Writ. Greg Daniels and Jennifer Coletta. Dir. Harold Ramis. NBC Universal, 2006. DVD.

Adorno, T.W. "How to Look at Television." The Quarterly of Film, Radio and Television. 8.3 (1954): 213-235.

Beeden, Alexandra and Joost de Bruin. "The Office: Articulations of National Identity in Television Format Adaptation." Television and New Media. 11.3 (2010): 3-19.

Bergson, Henri. Le Rire. Paris, FR: Presses Universitaires de France. Trans. Cloudesley Brereton and Fred Rothwell under the title Laughter. New York, NY: Macmillan, 1928. Print.

Cameron, Deborah. Good to Talk? Living and Working in a Communication Culture. London, UK: Sage Publications, 2000. Print.

Coleman, Robin R. Means. African American Viewers and the Black Situation Comedy. New York, NY: Garland, 2000. Print.

Creeber, Glen. The Television Genre Handbook: $2^{\text {nd }}$ Edition. London, UK: British Film Institute. 2008. Print.

Doane, Mary Ann. "Information, Crisis, Catastrophe." Logics of Television: Essays in Cultural Criticism. Ed. Patricia Mellencamp. Indianapolis, Indiana: Indiana University Press, 1990. Print.

Dreyfus, Herbert L. On the Internet. New York, NY: Routledge, 2001. Print.

Ellis, John. Seeing Things: Television in the Age of Uncertainty. NY, New York: I.B. Tauris and Co Ltd, 2000. Print.

Fiske, John. "Moments of Television: Neither the Text nor the Audience." Remote Control: Television, Audiences and Cultural Power. Eds. Ellen Seiter, Hans Borchers, Gabrielle Kreutzner, Eva-Maria Warth. New York, NY: Routledge, 1991. Print.

Fiske, John and John Hartley. Reading Television. London, UK: Routledge, 2003. Print.

Freedman, Eric. "The Limits of the Cellular Imaginary." Flow TV: "Television in the Age of Media Convergence. Eds. Michael Kackman, Marnie Binfield, Matthew Thomas Payne, Allison Perlman, Bryon Sebok. New York, NY: Routledge, 2011, Print.

Freud, Sigmund. The Joke and Its Relation to the Unconscious. Trans. Joyce Crick. New York, NY: Penguin, 2002. Print.

"Game Changer." Modern Family: The Complete First Season. Writ. Christopher Lloyd and Steven Levitan. Dir. Kevin Rodney Sullivan. $20^{\text {th }}$ Century Fox Television, 2010. DVD. 
Giddens, Anthony. Modernity and Self-Identity: Self and Society in the Late Modern Age. California: Stanford University Press, 1991. Print.

Gitlin, Todd. "Prime-time Ideology: The Hegemonic Process in Television Entertainment." Social Problems. 26.3 (1979): 251-266.

Glasgow, R.D.V. "Madness, Masks, and Laughter: An Essay on Comedy." Mississauga, Canada: Associated University Press, 1995. Print.

Goffman, Erving. The Presentation of Self in Everyday Life. New York, NY: Doubleday, 1959. Print.

Goffman, Erving. Interaction Ritual: Essays on Face-to-Face Behavior. Garden City, NY: AnchorBooks, 1967. Print.

Hartley, John. Television Truths: Forms of Knowledge and Power. Oxford, UK: Wiley Blackwell Publishers, 2008. Print.

Hatfield, Elizabeth. "What it Means to be a Man: Examining Hegemonic Masculinity in Two and a Half Men." Communication, Culture and Critique. 3.4 (2010): 526-548.

Heimberg, R. "Trends in the prevalence of social phobia in the United States: a synthetic cohort analysis of changes over four decades." European Psychiatry. 15.1 (2009): 29-37.

Hokenson, Jan W. The Idea of Comedy: History, Theory, Critique. Cranbury, NJ: Rosemont Publishing \& Printing Corp, 2005. Print.

Jhally, Sut and Justin Lewis. Enlightened Racism: The Cosby Show, Audiences and the Myth of the American Dream. Boulder, CO: Westview Press, 1992. Print.

Kotsko, Adam. Awkwardness. Hampshire, UK: Zero Books, 2010. Print.

Knorr Cetina, Karin. "Sociality with Objects: Social Relations in Postsocial Knowledge Societies." Theory, Culture and Society. 14.4 (1997): 1-30.

Licoppe, Christian and Zbigniew Smoreda."Are Social Networks Technologically Embedded?" Social Networks 27.4 (2005): 317-335.

Malinowski, Branislaw. "On Phatic Communication." The Discourse Reader. Eds. Adam Jaworski and Nikolaus Coupland. New York, NY: Routledge, 2006. Print.

Marc, David. Comic Visions: Television Comedy and American Culture. Massachusetts: Blackwell Pub, 1997. Print.

McAleer, Sean. "The Virtues of Humor: What The Office can teach us about Aristotle's Ethics." The Office and Philosophy: Scenes from the unexamined life. Ed. J. Jeremy Wisnewski. Malder, MA: Blackwell, 2008. Print.

Mellencamp, Patricia. "TV Time and Catastrophe or Beyond the Pleasure Principle of Television." Logics of Television: Essays in Cultural Criticism. Ed. Patricia Mellencamp. Bloomington, IN: Indiana University Press, 1990. Print. 
"Merger." The Office: The Complete Second Season. Writ. Ricky Gervais and Stephen Merchant. Dir. Ricky Gervais and Stephen Merchant. BBC, 2001. DVD.

Miller, Vincent. "New Media, Networking and Phatic Culture." Convergence. 14.4 (2008): 387 -400 .

Mills, Brett. Television Sitcom. London, UK: British Film Institute, 2005. Print.

Mirzoeff, Nicholas. Seinfeld. London, UK: British Film Institute. 2007. Print.

Morreall, John. Comedy, Tragedy, Religion. New York, NY: State University of New York Press, 1999. Print.

Nietzsche, Friedrich. The Gay Science. Trans. Walter Kaufmann. New York, NY: Vintage, 1882/1974. Print

Nys, Thomas. "Darkies, Dwarves and Benders: Political (In)Correctness in The Office." The Office and Philosophy: Scenes from the unexamined life. Ed. J. Jeremy Wisnewski. Malder, MA: Blackwell, 2008. Print.

O'Neill, Patrick. The Comedy of Entropy: Humour/Narrative/Reading. Toronto, Canada: University of Toronto Press, 2001. Print.

Piersen, David P. "A Show About Nothing: Seinfeld and the Comedy of Manners." Journal of Popular Culture. 34.1 (2000): 49-63.

Puro, Jukka-Pekka. "Finland: A Mobile Culture." Perpetual Contact: Mobile Communication, Private Talk, PublicPerformance. Eds. James E.Katz and Mark Aakhus. Cambridge, UK: Cambridge University Press, 2002. Print.

Savorelli, Antonio. Beyond Sitcom: New Directions in American Television Comedy. Jefferson, NC: McFarland and Co., 2010. Print

Silverstone, Roger. "Television, Ontological Security and the Transitional Object." Media, Culture and Society. 15.4 (1993): 573-598.

Silverstone, Roger. Television and Everyday Life. New York, NY: Routledge, 1994. Print.

Sutton, Dana. The Catharsis of Comedy. Lanham, MD: Rowand and Littlefield Pub, 1994, Print.

Sypher, Wylie. "The Meanings of Comedy." Comedy. Ed. Wylie Sypher. Garden City, NY: John Hopkins University Press, 1980. Print.

Thompson, Ethan. "Comedy Verité: The Observational Documentary Meets the Televisual Sitcom." Velvet Light Trap. 60 (2007): 63-72.

Turkle, Sherry. Alone Together. New York, NY: Basic Books, 2011. Print.

Turkle, Sherry. Life on the Screen: Identity in the Age of the Internet. New York, NY: Simon and Schuster Publishing, 1995. Print. 
Tinker, Emma. "Talking Cookie Jars and Tongue-Tied Bodies: Posthumanism and The Office." Journal of Popular Culture. 42.4 (2009): 756-772.

Virilio, Paul. Politics of the Very Worst. New York, NY: Semiotext(e), 1999. Print.

Williams, Raymond. Television: Technology and Cultural Form. New York, NY: Routledge, 2003. Print.

Wittel, Andreas. "Toward a Network Sociality." Theory, Culture and Society. 18.6 (2001): 51 -76 .

Yurchisin, Jennifer, Watchravesringkan, Kittichai and Deborah Brown McCabe. "An exploration of identity re-creation in the context of internet dating." Social Behavior and Personality. 33.8 (2005): $735-750$.

Zhao, Shanyan, Grasmuck, Sherri and Jason Martin. "Identity construction on Facebook: Digital empowerment in anchored relationships." Computers in Human Behavior. 24.5 (2008): 1816-1836. 